\title{
Coexistence between Zostera marina and Zostera japonica in seagrass beds of the Seto Inland Sea, Japan
}

\author{
Kenji Sugimoto ${ }^{1 *}$, Yoichi Nakano ${ }^{1}$, Tetsuji Okuda², Satoshi Nakai ${ }^{3}$, Wataru Nishijima ${ }^{4}$ and Mitsumasa Okada ${ }^{5}$
}

\begin{abstract}
Background: There have been many studies on the growth conditions of Zostera marina and Zostera japonica, but few studies have examined how spatial and temporal factors affect growth in established seagrass beds or the distribution range and shoot density. This study aims to clarify the factors that determine the temporal and spatial distribution of Zostera marina and Zostera japonica in the Seto Inland Sea east of Yamaguchi Prefecture.

Methods: The study site is in Hiroshima Bay of the Seto Inland Sea, along the east coast of Yamaguchi Prefecture, Japan. We monitored by diving observation to confirm shoot density, presence or absence of both species and observed water temperature, salinity by sensor in study sites.

Results: The frequency of occurrence of Zostera marina was high in all seasons, even in water depths of D.L. +1 to $-5 \mathrm{~m}$ ( $80 \pm 34 \%$ to $89 \pm 19 \%$; mean \pm standard deviation), but lower (as low as $43 \pm 34 \%$ ) near the breakwall, where datum level was 1 to $2 \mathrm{~m}$, and it was further reduced in datum level $-5 \mathrm{~m}$ and deeper. The frequency of occurrence of Zostera japonica was highest in water with a datum level of +1 to $0 \mathrm{~m}$. However, in datum level of $0 \mathrm{~m}$ or deeper, it became lower as the water depth became deeper. Datum level $+1 \mathrm{~m}$ to $0 \mathrm{~m}$ was an optimal water depth for both species. The frequency of occurrence and the shoot density of both species showed no negative correlation. In 2011, the daily mean water temperature was $10^{\circ} \mathrm{C}$ or less on more days than in other years and the feeding damage by S. fuscescens in the study sites caused damage at the tips.

Conclusions: We considered that the relationship between these species at the optimal water depth was not competitive, but due to differences in spatial distribution, Zostera marina and Zostera japonica do not influence each other due to temperature conditions and feeding damage and other environmental conditions. Zostera japonica required light intensity than Zostera marina, and the water depth played an important role in the distribution of both species.
\end{abstract}

Keywords: Zostera marina, Zostera japonica, Coexistence of distribution, Low water temperature, Herbivorous fishes

\section{Background}

Zostera beds are major primary producers in estuarine and coastal areas, and they support large and diverse faunal assemblages. These beds are excellent habitats for many commercial fishes, providing hatcheries and nurseries for juvenile fish (Kikuchi 1980; Pollard 1984; Orth et al. 1984). Zostera beds in the Seto Inland Sea, Japan are made up of Zostera marina and Zostera japonica (Biodiversity Center of Japan 2008). In Japan, Z. marina is found from Hokkaido to Kyushu, and Z. japonica is

\footnotetext{
* Correspondence: k-sugimoto@ube-k.ac.jp

${ }^{1}$ National Institute of Technology, Ube College, Ube, Japan

Full list of author information is available at the end of the article
}

distributed from Hokkaido to the Ryukyu Islands (Aioi 1998; Omori 2000; Aioi and Nakaoka 2003). The distribution of species and shoot density varies with the life history of the seagrass, environmental conditions, and by year (Sugimoto et al. 2008; Harrison 1982; Abe et al. 2004). $Z$. marina is taller and has longer and wider leaves than $Z$. japonica, while the shoot density of $Z$. japonica is higher than that of $Z$. marina (Arasaki 1950a, b). Therefore, the dominant species and distribution of seagrass is an important factor in determining the character of the seagrass bed. In particular, there are reports in recent years of $Z$. japonica increasing its presence in seagrass beds (Mach et al. 2014; Shafer et al. 2014). 
Physical factors also play a role in the distribution and growth of Zostera beds. The upper part of seagrass is affected by water turbulence, and the lower part is affected by photosynthesis inhibition (Dennison and Alberte 1985; Duarte 1991; Mach et al. 2010; Kendrick et al. 2002). The habitats of $Z$. marina and $Z$. japonica are affected by salinity and depth (Greve and Krausen-Jensen 2005; Morita et al. 2010; Abe et al. 2009; Shafer et al. 2011). For example, in the summer, $Z$. marina growth becomes difficult when the daily mean water temperature is $28{ }^{\circ} \mathrm{C}$ or more. Seagrass reproduction occurs by branching of rhizomes or seed germination. In reproduction by seed, the germination rate of seagrass is higher when the water temperature is lower, and it is highest when the water temperature has been below about $10{ }^{\circ} \mathrm{C}$.

There have been many studies on the growth conditions of $Z$. marina and $Z$. japonica, but few studies have examined how spatial and temporal factors affect growth in established seagrass beds or the distribution range and shoot density.

This study aims to clarify the factors that determine the temporal and spatial distribution of $Z$. marina and $Z$. japonica in the Seto Inland Sea east of Yamaguchi Prefecture.

\section{Methods}

\section{Study sites}

The study site is in Hiroshima Bay of the Seto Inland Sea, along the east coast of Yamaguchi Prefecture, Japan $\left(34^{\circ} 00^{\prime} \mathrm{N}, 132^{\circ} 12^{\prime} \mathrm{E}\right)$ (Fig. 1). The Imazu and Monzen rivers flow into the bay near the study site, and at times of heavy rain about $15 \mathrm{~km}$ to the north, the salinity is temporarily low. Salinity in the vicinity of the study site ranged from 28 to $32 \%$. The seawater in the study area had low transparency, and water mixing is low at the north side of the bay (Kawanishi 1999). At the bottom

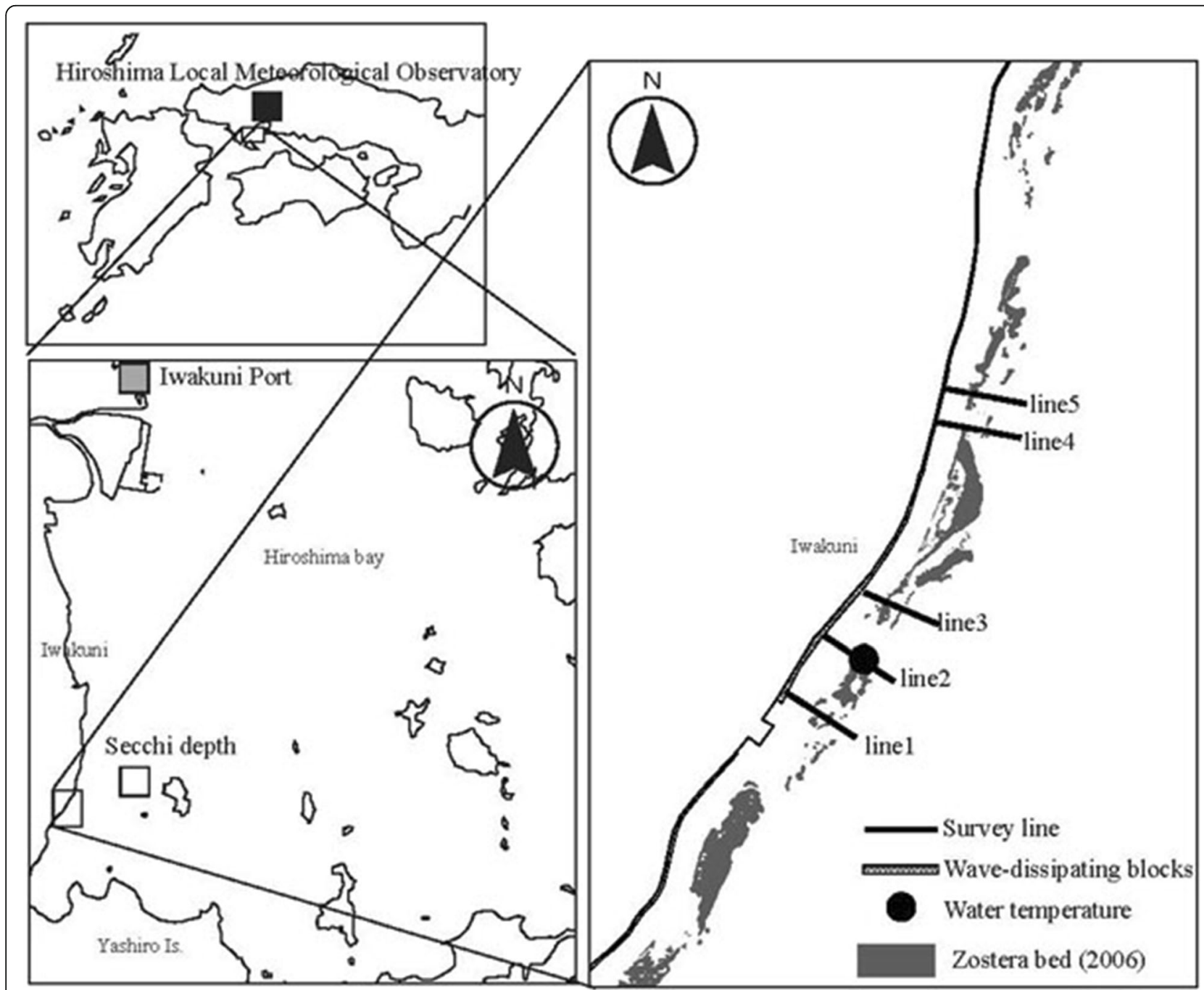

Fig. 1 Study site and survey lines 
layer, the flow rate at the study site was a mean of $3 \mathrm{~cm} \cdot \mathrm{s}^{-1}$, and a maximum of about $35 \mathrm{~cm} \cdot \mathrm{s}^{-1}$, with a back and forth flow along the coastline. The flow at Obatakeseto, which is about $5 \mathrm{~km}$ southwest of the study site, is very fast and becomes about $250 \mathrm{~cm} \cdot \mathrm{s}^{-1}$ during the faster spring tide. In the vicinity of the study site, seagrass grows to a range of about $200 \mathrm{~m}$ from the shore, but at about $15 \mathrm{~km}$ north, near Iwakuni airport, south Ohbatake seagrass beds have formed almost continuously up to $4 \mathrm{~km}$ from the shore. Sea bottom materials in Zostera bed had silt and clay percentage of $5-8 \%$ and sand percentage of $90-91 \%$.

Survey lines were designated as starting at the base point of the wave-dissipating blocks (breakwater) and extending offshore perpendicular to the shoreline. The length of each survey line and the number of sampling points along each survey line are given in Table 1. Survey lines at the south side of the study area had more sampling points. In December 2010, water depth along the survey lines was measured relative to a reference point in Iwakuni Port and reported as depth limit (datum level) recorded in meters (Fig. 2).

Monitoring of seagrass beds was conducted from December 2010 to October 2013 at a frequency of 2 to 5 months.

\section{Monitoring of Zostera bed}

Seagrass beds in the survey area were monitored at the five survey lines near Iwakuni, Yamaguchi Prefecture. Monitoring was carried out by diving observation to confirm the presence or absence of $Z$. marina and $Z$. japonica. Water depth along the monitoring lines was measured relative to a reference point in Iwakuni Port and was reported as D.L. recorded in meters from December 2010 to October 2013. Observations were made every $10 \mathrm{~m}$. Survey findings for D. L. in the range of +1 to $0 \mathrm{~m}$ and in the range of 0 to $-7 \mathrm{~m}$ were examined separately. The number of shoots in quadrats ( $Z$. marina $50 \times 50 \mathrm{~cm}, Z$. japonica $10 \times 10 \mathrm{~cm}$ ) was measured. Shoot height was measured for up to ten shoots of each $Z$. marina and Z. japonica in the range of D.L. +1 to $0 \mathrm{~m}$. The shoot height was measured as the longest leaf on the vegetative shoots, and if there were no vegetative shoots, seedling shoots were measured.

\section{Environmental conditions}

Temperature data loggers (Onset Computer Corporation; TidbiT v2) were used to take measurements at a

Table 1 Length of survey lines and number of sampling points

\begin{tabular}{lllllll}
\hline & Line 1 & Line 2 & Line 3 & Line 4 & Line 5 \\
\hline The length of the survey line $(\mathrm{m})$ & 150 & 140 & 130 & 110 & 110 \\
The number of research point & 16 & 15 & 14 & 12 & 12 \\
\hline
\end{tabular}

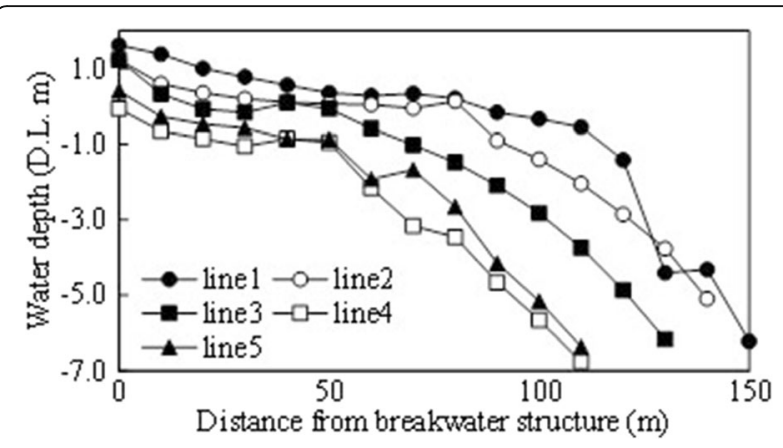

Fig. 2 Water depth based on D.L. along lines 1 to 5 (the reference point in Iwakuni Port)

height of $20 \mathrm{~cm}$ from the bottom of the sea at line 2 to $120 \mathrm{~m}$ from the breakwater every $10 \mathrm{~min}$ from January 2010 to December 2013. Solar irradiation data collected at Hiroshima Local Meteorological Observatory $50 \mathrm{~km}$ north-northeast of the study site, and Secchi depth was collected $3 \mathrm{~km}$ to the west of the study site in a Yamaguchi Prefecture public waters survey.

\section{Results}

\section{Distribution of seagrass, height, and shoot density}

Figure 2 shows the horizontal distance from the breakwater and the depth at each sampling point along each survey line in the seagrass beds. The flat water depth was ranged from +1.0 to $-1.0 \mathrm{~m}$ to a distance of 50 to $80 \mathrm{~m}$ along each survey line and then became gradually lower offshore. The survey lines at the south end of the survey area showed a steeper drop in water depth.

Figure 3 shows the frequency of occurrence of Z. marina and $Z$. japonica along the survey lines in different water depths by season. The occurrence of both species was in the range of D.L. +1 to $-7 \mathrm{~m}$.

The frequency of occurrence of $Z$. marina was high in all seasons, even in water depths of D.L. +1 to $-5 \mathrm{~m}$ ( $80 \pm 34 \%$ to $89 \pm 19 \%$; mean \pm standard deviation), but lower (as low as $43 \pm 34 \%$ ) near the breakwall, where D.L. was from 1 to $2 \mathrm{~m}$, and it was further reduced in D.L. $-5 \mathrm{~m}$ and deeper. In June 2011, there was no difference in the frequency of occurrence of $Z$. marina for D.L. in the range of +1 to $-5 \mathrm{~m}$, in August 2011, the frequency of occurrence in June 2013 was $95 \pm 9 \%$, which was higher than $80 \pm 23 \%$ of other times, and this was a statistically significant difference $(P<0.05)$.

The frequency of occurrence of $Z$. japonica was highest in water with a D.L. of +1 to $0 \mathrm{~m}$. However, in D.L. of $0 \mathrm{~m}$ or deeper, it became lower as the water depth became deeper. For $Z$. japonica, the seasonal difference was less $(P>0.85)$. When the frequency of occurrence for both species throughout the year is more than $50 \%$ at a water depth, the optimal water depth for $Z$. marina 

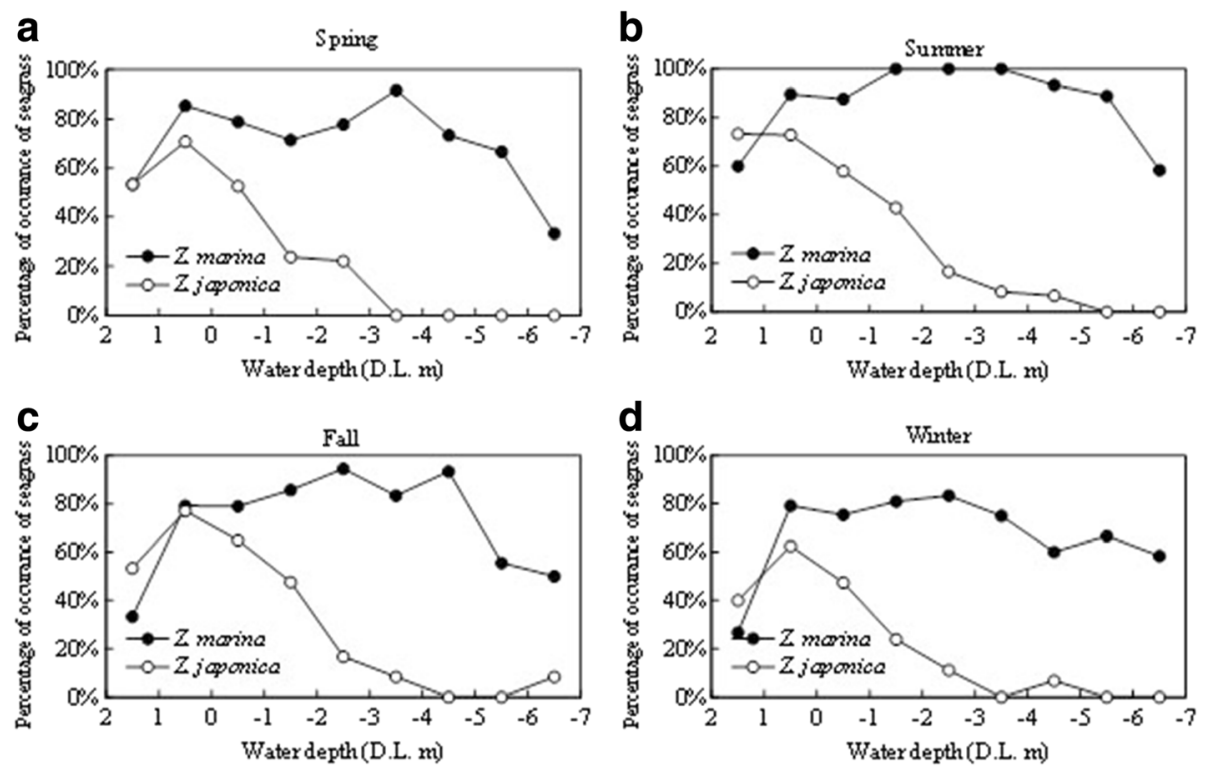

Fig. 3 Seagrass distribution at water depth based D.L. in each season

and $Z$. japonica is taken as D.L. from +1 to $-5 \mathrm{~m}$ and +1 to $0 \mathrm{~m}$, respectively.

Figure 4 shows the change in the frequency of occurrence at D.L. $+1 \sim 0 \mathrm{~m}$, which was an optimal water depth common to Z. marina and Z. japonica from December 2010 to October 2013, but in deeper water (D.L. 0 $-7 \mathrm{~m}), Z$. marina was more common.

The frequency of occurrence was $83 \pm 11 \%$ for $Z$. marina at the common optimal water depth, and the frequency of occurrence for $Z$. japonica was $70 \pm 10 \%$; there were no significant changes throughout the period of the survey. In the D.L. from 0 to $-7 \mathrm{~m}$, the frequency of occurrence of $Z$. marina was $77 \pm 31 \%$, and the frequency of occurrence of $Z$. japonica was $17 \pm 22 \%$, and in December 2012 and later, it was on the increase.

Figure 5 shows the changes in shoot density of $Z$. marina and $Z$. japonica at $\mathrm{DL}+1$ to $0 \mathrm{~m}$ for both species from December 2010 to October 2013. The shoot density of $Z$. marina and $Z$. japonica decreases rapidly from
April or June 2011 to February 2012, and then shoot density was restored.

Figure 6 shows the correlation between the frequency of occurrence and shoot density for Z. marina and Z. japonica from $\mathrm{DL}+1$ to $0 \mathrm{~m}$ using data from December 2010 to October 2013. The frequency of occurrence and the shoot density of both species showed no negative correlation, as would be expected in a competitive relationship. Therefore, we considered that the relationship between these species at the optimal water depth was not competitive.

\section{Water temperature and solar irradiation}

There were no significant variations in the frequency of occurrence of both species at the optimal water depth, and the shoot density showed great large variation of rapid decline and subsequent recovery from the summer of 2011 to the winter of 2012. We examined shoot density and photosynthesis data for factors that affect growth
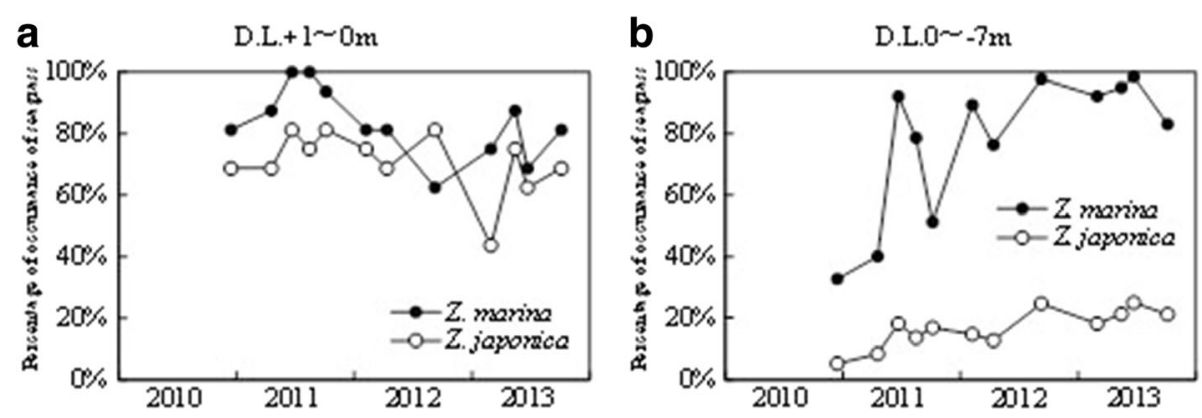

Fig. 4 Change in occurrence distribution of Z. marina and Z. japonica at two optimal water depths 


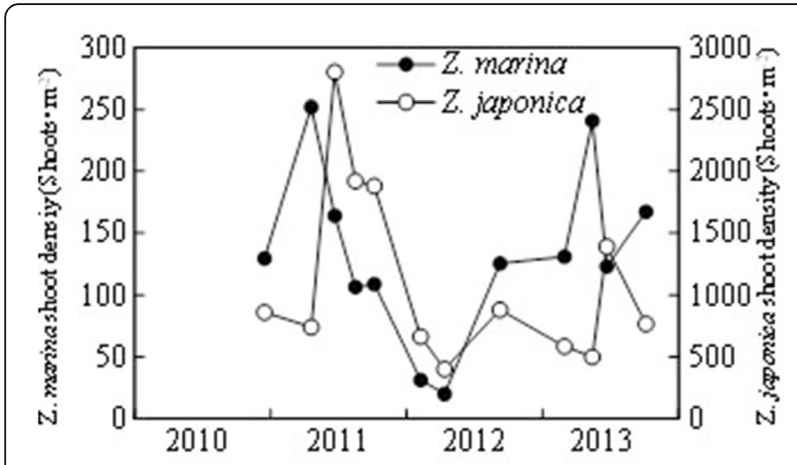

Fig. 5 Distribution of $Z$. marina and Z. japonica shoot density at an optimal water depth (D.L. +1 to $0 \mathrm{~m}$ ) throughout the study period

and germination. Figure 7 shows the changes in mean daily water temperature from January 2010 to December 2013. In October 2011 or later, the shoot density of both species decreased rapidly. However in 2011, there were no observations of $28{ }^{\circ} \mathrm{C}$ (Tiina et al. 2014) or higher water temperatures which affect the growth of seagrass, and annual mean water temperature ranged from 17.1 to $17.9{ }^{\circ} \mathrm{C}$. Since there was no statistically significant difference by year, annual water temperature was not considered to be a factor for the decrease in shoot density, and annual water temperature was not a direct cause of the decrease in shoot density in both species after October 2011.

Figure 8 shows the number of days in each year from 2010 to 2013 for which the daily mean water temperature was lower than $10{ }^{\circ} \mathrm{C}$; a temperature that may affect the germination of seagrass (Abe et al. 2009; Kawasaki et al. 1986). In 2011, the shoot density of $Z$. marina and $Z$. japonica was higher until June before the summer, and the number of days on which the daily mean water temperature was lower than $10^{\circ} \mathrm{C}$ was higher than in any other year at 43 days. In 2011, the daily mean water temperature was lower than $10{ }^{\circ} \mathrm{C}$ from January 16 to March 26, and 2011 was the only year in which the water temperature was less than $10{ }^{\circ} \mathrm{C}$ at the end of March.

Figure 9 shows the daily mean solar irradiation at the Hiroshima Local Meteorological Observatory from January 2010 to December 2013. Annual mean of daily mean solar irradiation ranged from 13.6 to $14.6 \mathrm{MJ} \cdot \mathrm{m}^{-2}$, and there was no significant difference by year. Similar to the mean water temperature, it was considered that there was no direct effect of solar irradiation changes on the rapid decline of seagrass since October 2011.

The estimated lower depth limit of $Z$. marina and the Secchi depth $\left(S_{d}, m\right)$ from January 2010 to December 2013 at a point $3 \mathrm{~km}$ east of the study site is shown in Fig. 10. The estimated lower depth limit distribution of $Z$. marina $\left(Z_{\mathrm{c}}, \mathrm{m}\right)$ was calculated using the light attenuation coefficient $\left(K, \mathrm{~m}^{-1}\right)$ as follows (Duarte 1991).

$$
Z_{\mathrm{c}}=1.86 \mathrm{~K} \text { and } K=1.7 / S_{\mathrm{d}} \text {. }
$$

The annual mean $S_{\mathrm{d}}$ and $Z_{\mathrm{c}}$ are reported in Table 2 . The $S_{\mathrm{d}}$ and $Z_{\mathrm{c}}$ in 2010 were $6.3 \pm 1.6 \mathrm{~m}$ and $6.8 \pm 1.8 \mathrm{~m}$, respectively. These values gradually increased after 2010, the $S_{\mathrm{d}}$ and $Z_{\mathrm{c}}$ in 2013 were $8.9 \pm 2.9 \mathrm{~m}$ and $9.8 \pm 3.1 \mathrm{~m}$, respectively. Therefore, since 2010, the daily mean solar irradiation is due to having a deeper $S_{\mathrm{d}}$, and every year, the light conditions for the growth of $Z$. marina and $Z$. japonica were considered to improve.

Figure 11 shows the changes in salinity from December 2010 to October 2013. The salinity in the study period ranged from 29.3 to 32.4 PSU and never decreased below 10 PSU (Kawasaki et al. 1986); a level that affects the growth of $Z$. marina.

\section{Feeding damage}

In October 2011, the upper portions of many of the $Z$. marina appeared to have had feeding damage, as shown in Fig. 12. Therefore, shoots height of $Z$. marina and $Z$. japonica was examined from December 2010 to October 2013, as an indicator of feeding damage (Fig. 13). The
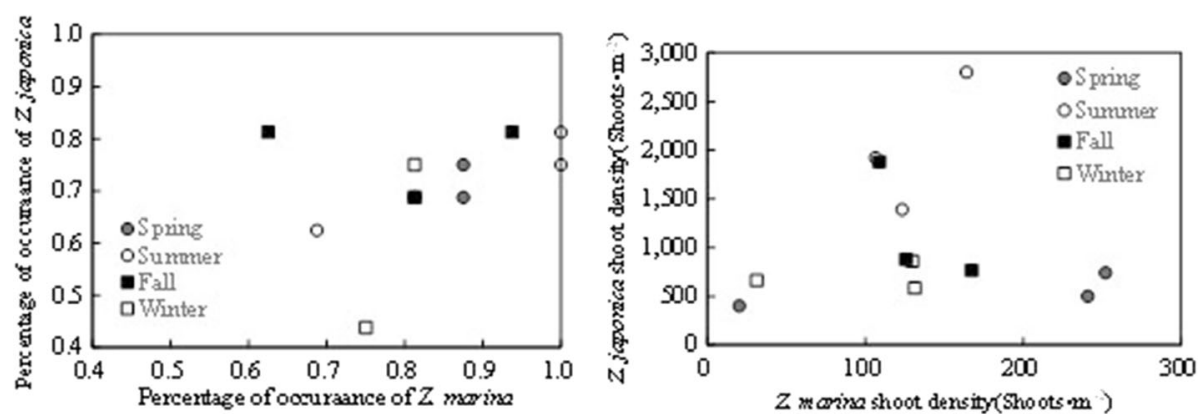

Fig. 6 Correlation between the occurrence percentage and shoots density of Z. marina and Z. japonica at an optimal water depth (D.L. +1 to $0 \mathrm{~m}$ ) by season 


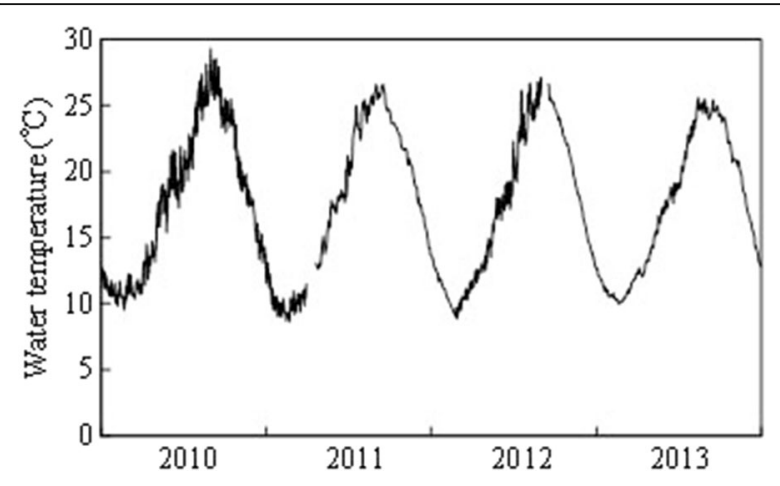

Fig. 7 Seawater temperature at study site

mean shoot height (stomach contents in fish were not confirmed to be Z. marina) in August 2011 was $50 \mathrm{~cm}$, after which feeding damage reduced it to $23 \mathrm{~cm}$. The mean shoot height of $Z$. japonica in August 2011 and in October 2011 was 23 and $15 \mathrm{~cm}$, respectively. The shoot height of $Z$. japonica also decreased in the same way as the shoot height of $Z$. marina. In the Seto Inland Sea, herbivorous fishes, Siganus fuscescens, were observed in 2011 to cause feeding damage to the seagrass bed, and feeding damage to $Z$. marina was also observed in Hiroshima Bay (Sugimoto et al.). Although not directly observed, the feeding damage by $S$. fuscescens in the study sites caused damage at the tips, and damage was assumed to cause a decrease in shoot density for both species.

\section{Discussion}

The distribution of $Z$. japonica is mostly in the intertidal zone, while that of $Z$. marina is mostly in the subtidal zone (Mach et al. 2010), but the factors affecting these differences in distribution were not clarified. Z. marina and $Z$. japonica in D.L. $-4 \mathrm{~m}$ and shallower had overlapping distribution, and for D.L. from +1 to $0 \mathrm{~m}$ showed high occurrence rate for both species. In other words, $Z$. japonica grew at water depths that were also included in the range of Z. marina. Zostera marina had greater

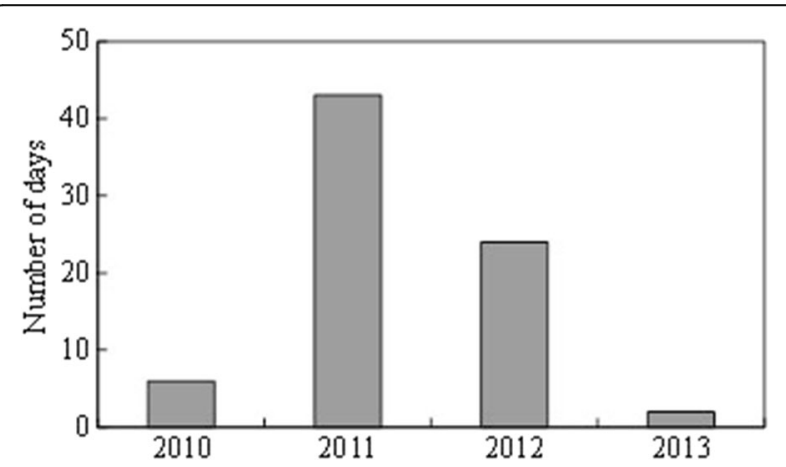

Fig. 8 Number of days with daily mean water temperature below $10^{\circ} \mathrm{C}$

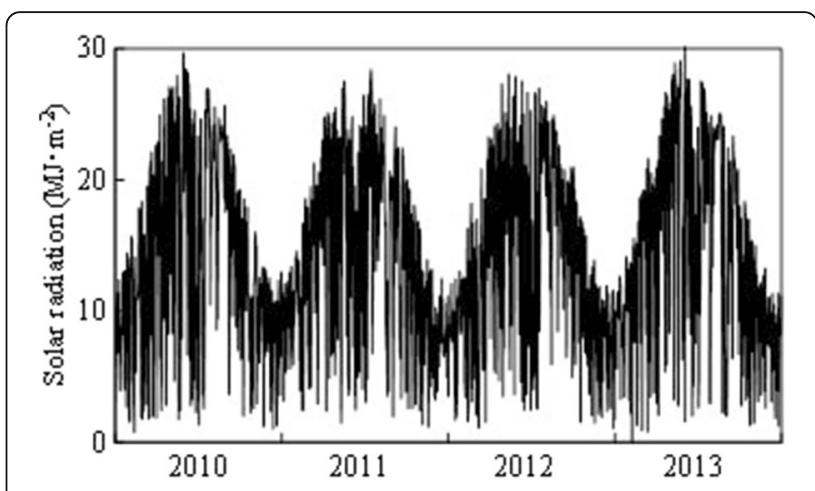

Fig. 9 Solar irradiation recorded at Hiroshima Local Meteorological Observatory

shoot height than $Z$. japonica, and these species are assumed to have a competitive relationship based on $Z$. marina growing higher and shading $Z$. japonica. However, in the optimal water depths, occurrence frequency and shoot densities are similar for both species, and the lack of a negative correlation suggests that the growth of both species is independent.

The subtidal is deeper than the optimal water depth of both species, and the seagrass distribution, and thick seagrass ( $Z$. marina) which grows tall and has wide leaves shades short seagrass ( $Z$. japonica and Ruppia maritima), inhibiting the photosynthesis and possibly the distribution of short seagrass. A negative correlation was observed in the biomass of tall Z. marina and short Ruppia maritima in the Chesapeake Bay subtidal zone (Orth 1977). Z. marina has limited light due to competition from algae (Sugimoto et al. 2007). When $Z$. japon$i c a$ of the subtidal is subjected a light limitation due to shading by leaves of $Z$. marina at the study site, there is little difference in the light compensation point of $Z$. marina and $Z$. japonica, the difference between the plant heights is low, and the distribution of $Z$. japonica by water depth in October 2011, April and June 2012 will surpass that of $Z$. marina. However, even in this

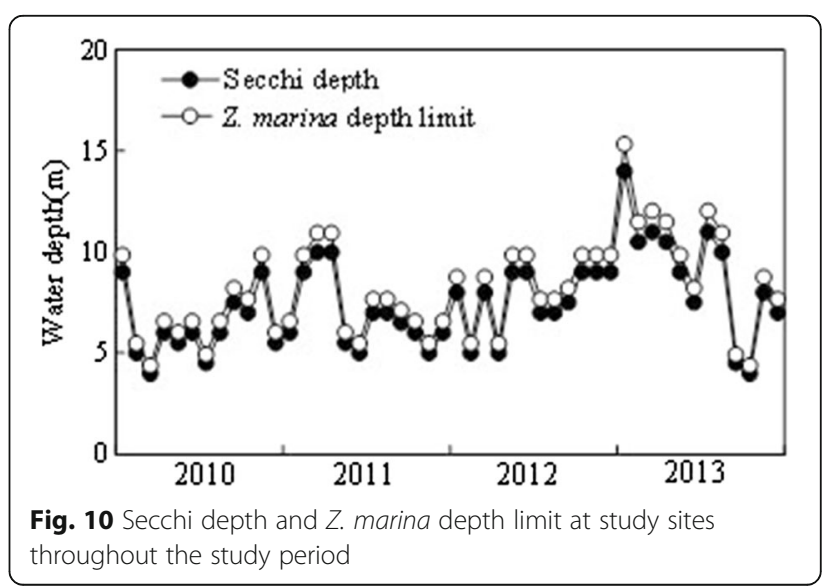


Table 2 The annual mean value of Secchi depth and estimated lower depth of Z. marina

\begin{tabular}{lllll}
\hline & 2010 & 2011 & 2012 & 2013 \\
\hline Secchi depth $(\mathrm{m})$ & $6.3 \pm 1.6$ & $6.9 \pm 1.8$ & $7.7 \pm 1.5$ & $8.9 \pm 2.9$ \\
Z. marina depth limit $(\mathrm{m})$ & $6.8 \pm 1.8$ & $7.6 \pm 2.0$ & $8.4 \pm 1.6$ & $9.8 \pm 3.1$ \\
\hline
\end{tabular}

period, the water depth of $Z$. japonica distribution had not changed greatly. Compared to Z. marina, Z. japonica was not distributed in deep water. In the study sites, the shear stress was reduced in deeper water. Under calm water conditions, diatoms and sediment adhere to the leaves of $Z$. marina and $Z$. japonica, and moderate disturbance is necessary to avoid growth inhibition (Shimaya et al. 2004; Sugimoto et al. 2003). Z. japonica habitats in the deep water of Tokyo Bay had higher bottom shear stress values than in non-vegetated areas. Epiphytic Ectocarpus siliculosus (Fig. 14), a mobile brown algae and Diffalaba picta picta (Fig. 15), a conch, are epiphytic and both were observed in the study site. No quantitative data on the occurrence frequency or levels of E. siliculosus and D. picta picta were collected; however, there is a possibility that they affected the distribution of $Z$. japonica in the subtidal zone. We could not confirm the influence on the growth distribution due to the coexistence between $Z$. marina and $Z$. japonica. However, it was clear that the water depth was an important factor determining the distribution of these species. The frequency of occurrence of $Z$. japonica was decreasing from D.L. $0 \mathrm{~m}$. In addition, the frequency of occurrence of $Z$. marina was decreasing from D. L. $-4 \mathrm{~m}$. Therefore, it was considered that the frequency of occurrence of these species were lowered in deep points due to the influence of the light condition. Z. japonica required light intensity than $Z$. marina, and the water depth played an important role in the distribution of these species.

In this study, no large annual variations in the frequency of occurrence of $Z$. marina and $Z$. japonica were found. On the other hand, great variation was observed

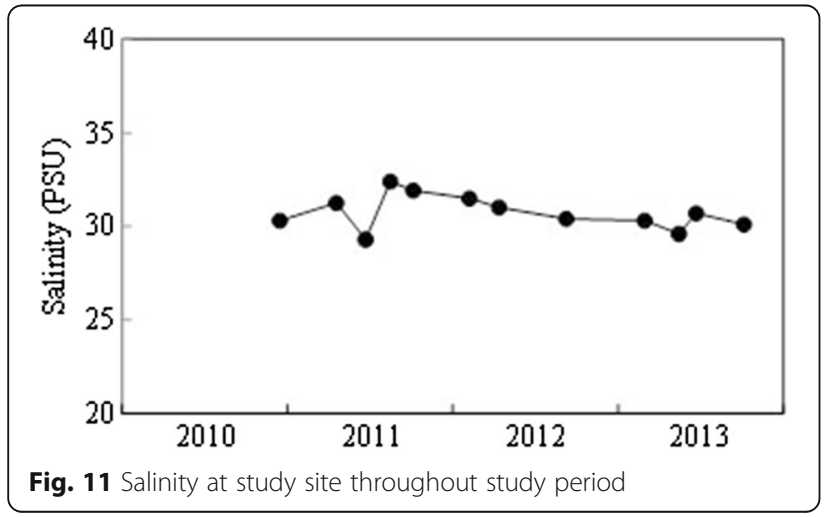

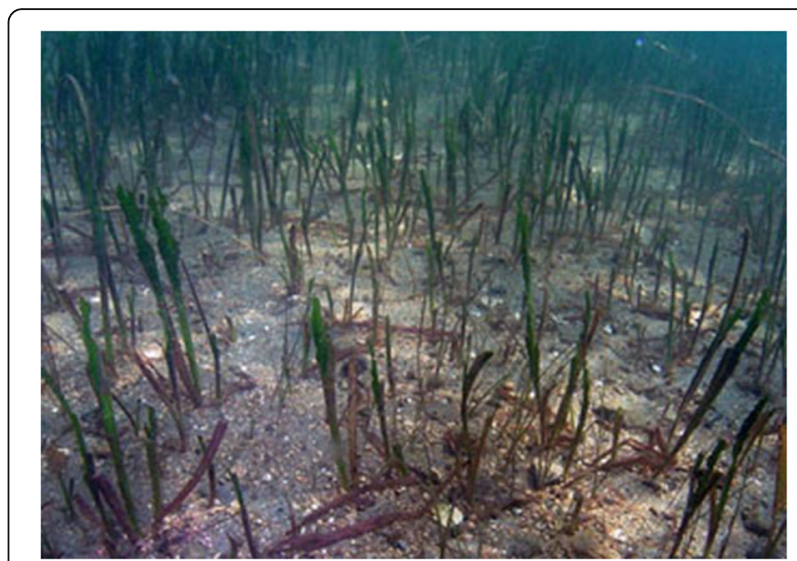

Fig. 12 Losses at the upper end of the seagrass leaves (October 2011:line 2)

in the shoot density. Z. marina and Z. japonica occurrence frequency were determined by the required growth light conditions (depth); however, they were less affected by other factors, and shoot density was sensitive to environmental factors. During the study period, in particular, feeding damage and low water temperature in winter were factors affecting shoot density.

When the seeds of $Z$. marina were kept at $14{ }^{\circ} \mathrm{C}$ and buried in sea sand in laboratory experiments, germination was $23 \%$, but germination at $9{ }^{\circ} \mathrm{C}$ or less was $66 \%$ or greater (Tiina et al. 2014). When the same test for the $Z$. japonica was conducted, germination rate at $23{ }^{\circ} \mathrm{C}$ and at $4{ }^{\circ} \mathrm{C}$ was 40 and $80 \%$, respectively (Kishima et al. 2011). Thus, a water temperature of $10{ }^{\circ} \mathrm{C}$ or less in the winter increases the germination rate and distribution of both species in spring. In the study site in 2011, the daily mean water temperature was $10{ }^{\circ} \mathrm{C}$ or less on more days than in other years. In particular, water temperature was lower in shallow water at low tide. Therefore, there is a possibility that a high germination rate of seagrass occurs in depths from D.L. +1 to $0 \mathrm{~m}$.

In Gozensaki-cho, Shizuoka Prefecture, leaves of Ecklonia cava were lost due to feeding damage by $S$. fuscescens, and

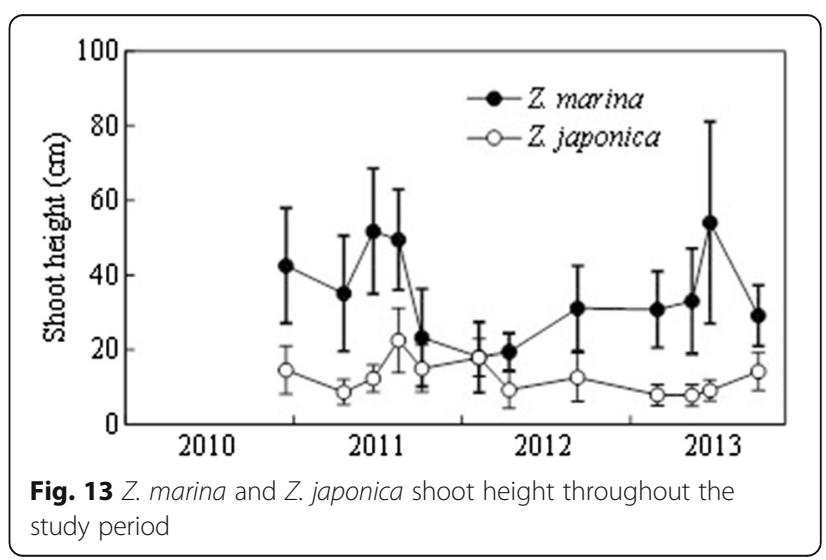




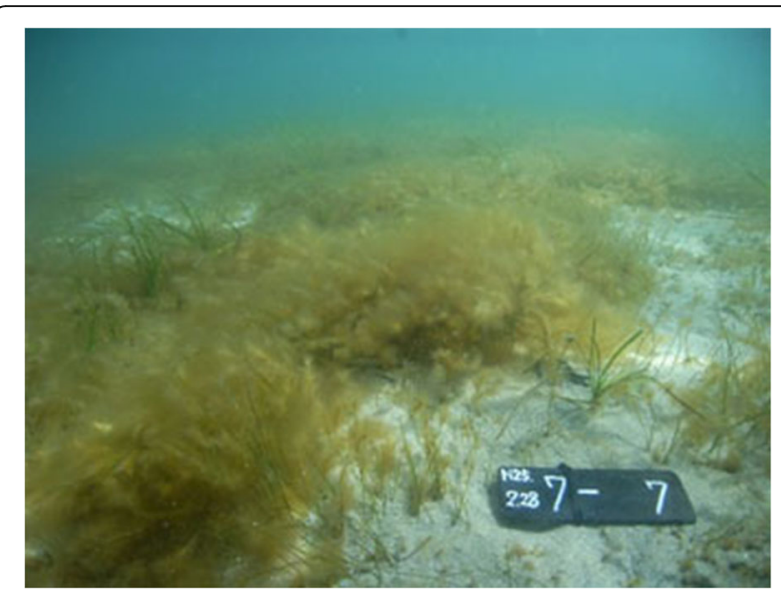

Fig. 14 E. siliculosus adhering to the leaves of Z. marina and Z. japonica (February 2013:line 2)

seagrass beds were in decline in a short period from October to November in 1998 (Masuda et al. 2000). The grazing of algae by $S$. fuscescens rose along with the rise in water temperature, and algae grazing became higher after the spawning from July to August. Examination of the amount of predation of $E$. cava by $S$. fuscescens using a water tank showed significantly increased predator weight at $25{ }^{\circ} \mathrm{C}$ before and after the heating has been observed (Kawamata and Masegawa 2006). The water temperature exceeded $25{ }^{\circ} \mathrm{C}$ in 2011 when S. fuscescens were thought to be grazing on eelgrass from August 2 to September 16, which is before and after spawning. In the period of August 17 to October 6, shoot height of $Z$. marina was shorter. The number of days for which the water temperature was higher than or equal to $25^{\circ} \mathrm{C}$ over the period of 2010 to 2013 was $38 \pm 16$ days, and in 2011 it was 42 days. Therefore, it is considered that water temperature in 2011 was not a factor in the increased

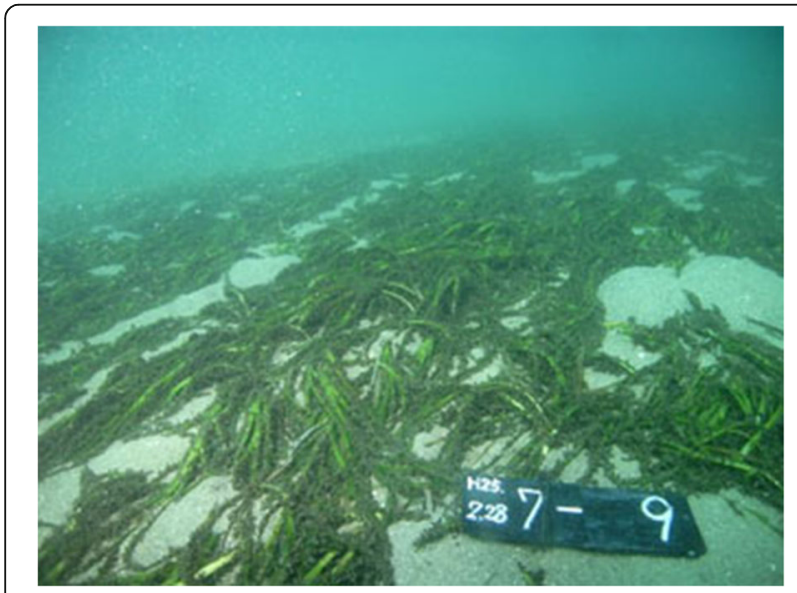

Fig. 15 Diffalaba picta picta adhering to the leaves of $Z$. marina (February 2013:line 4) predation pressure by $S$. fuscescens compared with other years.

The seagrass beds in the Seto Inland Sea, Japan east of Yamaguchi Prefecture are comprised of $Z$. marina and $Z$. japonica, which are competing species, but due to differences in spatial distribution, $Z$. marina and $Z$. japonica do not influence each other due to temperature conditions and feeding damage and other environmental conditions.

\section{Conclusions}

This study aims to clarify the factors that determine the temporal and spatial distribution of $Z$. marina and Z. japonica in the Seto Inland Sea east of Yamaguchi Prefecture. The specific conclusions derived from this study are as follows:

1) When the frequency of occurrence for both species throughout the year is more than $50 \%$ at a water depth, the optimal water depth for $Z$. marina and $Z$. japonica is taken as D.L. from +1 to $-5 \mathrm{~m}$ and from +1 to $0 \mathrm{~m}$, respectively. Thus, D.L. from +1 to $0 \mathrm{~m}$ was an optimal water depth for both species.

2) The frequency of occurrence and the shoot density of both species showed no negative correlation, as would be expected in a competitive relationship. Therefore, we considered that the relationship between these species at the optimal water depth was not competitive.

3) Z. japonica required light intensity than $Z$. marina, and the water depth played an important role in the distribution of both species.

4) In 2011, the mean water temperature, salinity, and solar irradiation were no difference between 2010 and 2013, however, the daily mean water temperature was $10{ }^{\circ} \mathrm{C}$ or less on more days than in other years. Therefore, there is a possibility that a high germination rate of seagrass occurs.

5) Since 2010, the daily mean solar irradiation is due to having a deeper $S_{\mathrm{d}}$, and every year, the light conditions for the growth of $Z$. marina and $Z$. japonica were considered to improve.

6) In October 2011, the feeding damage by S. fuscescens in the study sites caused damage at the tips, and damage was assumed to cause a decrease in shoot density for both species.

Abbreviations

D.L.: Datum level; Z. japonica: Zostera japonica; Z. marina: Zostera marina

Acknowledgements

Not applicable.

Funding

The design of the study and collection; National Institute of Technology, Ube College. 


\section{Availability of data and materials}

Analysis, Interpretation of data and In writing the manuscript; National Institute of Technology, Ube College.

\section{Authors' contributions}

KS carried out sea survey and performed the statistical analysis and drafted the manuscript. YN carried out sea survey. TO, SN, WN, and MO participated in the design of the study and helped to draft the manuscript. All authors read and approved the final manuscript.

\section{Competing interests}

The authors declare that they have no competing interests.

\section{Ethics approval and consent to participate}

Not applicable.

\section{Author details}

${ }^{1}$ National Institute of Technology, Ube College, Ube, Japan. ${ }^{2}$ Faculty of Science and Technology, Ryukoku University, Kyoto, Japan. ${ }^{3}$ Department of Chemical Engineering, Hiroshima University, Hiroshima, Japan. ${ }^{4}$ Environmental Research and Management Center, Hiroshima University, Hiroshima, Japan. ${ }^{5}$ The Open University of Japan, Chiba, Japan.

\section{Received: 4 January 2017 Accepted: 15 February 2017}

\section{Published online: 01 March 2017}

\section{References}

Abe, M., Hashimoto, N., Kurashima, A., \& Maegawa, M. (2004). Structure and seasonal change of the Zostera marina population on the coast of Matsunase, Mie Prefecture, central Japan. Nippon Suisan Gakkai, 70(4), 523-529.

Abe, M., Yokota, K., Kurashima, A., \& Maegawa, M. (2009). Temperature characteristics in seed germination and growth of Zostera japonica Ascherson \& Graebner from Ago Bay, Mie Prefecture, central Japan. Fisheries Science, 75, 921-927.

Aioi, K. (1998). On the red list species of Japanese seagrasses. Aquabiology, 20(1), $7-12$.

Aioi, K., \& Nakaoka, M. (2003). The seagrass of Japan. In E. P. Green \& F. T. Short (Eds.), World Atlas of Seagrasses (pp. 185-192). Berkley: University of California Press.

Arasaki, S. (1950a). Studies on the ecology Zostera marina and Z. nana (1). Nihon Suisan Gakkai, 15(10), 567-572.

Arasaki, S. (1950b). Studies on the ecology Zostera marina and Z. nana. Nihon Suisan Gakkai, 16(2), 70-76.

Biodiversity Center of Japan (2008) 7th Natural Environment Basic Research Shallow water ecosystem research (Seagrass bed research) Report (pp. 354-357)

Dennison, W. C., \& Alberte, R. C. (1985). Role of daily light period in the depth distribution of Zostera marina (eelgrass). Marine Ecology Progress Series, 25, $51-61$.

Duarte, C. M. (1991). Seagrass depth limits. Aquatic Botany, 40, 363-377.

Greve, T. M., \& Krausen-Jensen, D. (2005). Predictive modeling of eelgrass (Zostera marina) depth limit. Marine Biology, 146, 849-858.

Harrison, P. G. (1982). Seasonal and year-to-year variations in mixed intertidal populations of Zostera japonica Aschers. \& Graebn. and Ruppia maritima L. S. L. Aquatic Botany, 14, 357-371.

Kawamata, S., \& Masegawa, M. (2006). Effects of waves and temperature on feeding by the Rabbitfish Siganus Fsuscescens on Kelps Eisenia Bicyclis and Ecklonia cava. Fisheries Engineering, 46(1), 69-79.

Kawanishi, K. (1999). Characteristics of Water Exchange and Current Structures in North Area of Hiroshima Bay. Proceedings of Coastal Engineering, 46, 1041-1045.

Kawasaki, Y., lituka, T., Goto, H., Terawaki, T., Shimo, S. (1986) Effects of temperature on Zostera marina L. 1. Seed Germination and Seedling Development, Central Research Institute of Electric Power Industry, Rep. No. 485028

Kendrick, G. A., Aylward, M. T., Hegge, B. J., Cambridge, M. L., Hillman, K., Wyllie, A. , \& Lord, D. A. (2002). Changes in seagrass coverage in Cockburn Sound, Western Australia between 1967 and 1999. Aquatic Botany, 73, 75-87.

Kikuchi, T. (1980). Faunal relationships in temperate seagrass beds. In R. C. Phillips \& C. P. McRoy (Eds.), Holland book of Seagrass Biology (An Ecosystem Perspective, pp. 153-172). New York and London: Garland STPM Press.

Kishima, J., Harada, S., \& Sakurai, R. (2011). Suitable water temperature for seed storage of Zostera japonica for subtropical seagrass bed restoration. Ecological Engineering, 37, 1416-1419.
Mach, M.E., Wyllie-Echeverria S., Ward J. R. (2010) Distribution and potential effects of a non-native seagrass in Washington State Zostera japonica Workshop, Friday Harbor Laboratories, San Juan Island, WA, (pp. 14-16)

Mach, M. E., Wyllie-Echeverria, S., \& Chan, K. M. A. (2014). Ecological effect of a nonnative seagrass spreading in the Northeast Pacific: a review of Zostera japonica. Ocean \& Coastal Management, 102, 375-382.

Masuda, M., Tsunoda, T., Hayashi, Y., Nishio, S., Mizui, H., Horiuchi, S., \& Nakayama, Y. (2000). Decline of afforested Ecklonia Cava community by grazing of Herbivorous fish Siganus fuscescens. Fisheries Engineering, 37(2), 135-142.

Morita, T., Kokubu, H., Miyamatsu, A., Fujii, M., Kurashima, A., \& Maegawa, M. (2010). The effect of water temperature in the sediment and the desiccation period on the growth and survival of transplant seagrass Zostera japonica shoots in Mesocosm tank culture. Aquaculture Science, 58(2), 261-267.

Omori, Y. (2000). Japanese seagrasses. Distirbution and morphology. Aquabiology, 22(6), 524-532.

Orth, R. C. (1977). Effect of nutrient enrichment on growth of the eelgrass Zostera marina in the Chesapeake Bay Virginia USA. Marine Biology, 44, 187-194.

Orth, R. J., Heck, K. L. H., Jr., \& Montfrans, J. V. (1984). Faunal communities in seagrass beds: a review of the influence of plant structure and prey characteristics on predator-prey relationships. Estuaries, 7(4A), 339-350.

Pollard, D. A. (1984). A review of ecological studies on seagrass-fish communities, with particular reference to recent studies in Australia. Aquatic Botany, 18, 3-42.

Shafer, D. J., Kaldy, J. E., Sherman, T. D., \& Marko, K. M. (2011). Effects of salinity on photosynthesis and respiration of the seagrass Zostera japonica : a comparison of two established populations in North America. Aquatic Botany, 95, 214-220.

Shafer, D. J., Kaldy, J. E., \& Gaeckle, J. L. (2014). Science and management of the introduced seagrass Zostera japonica in North America. Environmental Management, 53, 147-162.

Shimaya, M., Sato, K., Nakase, K., Kuwae, T., \& Nakamura, Y. (2004). A study on physical environment suitable for Zostera Japonica growth. Annual Journal of Coastal Engineering, 51, 1031-1035.

Sugimoto, K., Asaoka, Y., Matsunami, D., Terawaki, T., Okada, M. (2012). Extinction of eelgrass off the coast of Iwakuni, Seto Inland Sea in decline period, Annual Journal of Japan Society on Water Environment, 46, 236.

Sugimoto, K., Hiraoka, K., Tamaki, H., Terawaki, T., Okada., M., (2003) Effects of Breakwater Construction on the Distribution of Transplanted Eelgrass Beds (Zostera marina L.), Proceedings of the 6th International EMECS Conference, (pp. 295-302)

Sugimoto, K., Hiraoka, K., Ohta, S., Niimura, Y., Terawaki, T., \& Okada, M. (2007). Effects of ulvoid (U/va spp.) accumulation on the structure and function of eelgrass (Zostera marina L.) bed. Marine Pollution Bulletin, 54, 1582-1585.

Sugimoto, K., Hiraoka, K., Tanida, K., Terawaki, T., \& Okada, M. (2008). Restration of eelgrass (Zostera marina L.) Beds by Filling up Borrow Pits with Natural Sediment. Journal of Japan Society on Water Environment, 31(4), 217-221.

Tiina, S., Morten, F. P., \& Christoffer, B. (2014). Population specific salinity tolerance in eelgrass (Zostera marina). Journal of Experimental Marine Biology and Ecology, 461, 425-429.

\section{Submit your next manuscript to BioMed Central} and we will help you at every step:

- We accept pre-submission inquiries

- Our selector tool helps you to find the most relevant journal

- We provide round the clock customer support

- Convenient online submission

- Thorough peer review

- Inclusion in PubMed and all major indexing services

- Maximum visibility for your research

Submit your manuscript at www.biomedcentral.com/submit
) Biomed Central 